\title{
Partnering for UN SDG \#17: a social marketing partnership model to scale up and accelerate change
}

\author{
Sinead Duane
}

Department of Marketing, National University of Ireland Galway, Galway and Ryan Institute, NUI Galway, Galway, Ireland

Christine Domegan

\author{
Department of Marketing, National University of Ireland, Galway, Ireland, and \\ Brendan Bunting \\ Department of Psychology, Faculty of Life and Health Sciences, \\ University of Ulster, Coleraine, UK
}

\begin{abstract}
Purpose - The United Nations (UN) 17 Sustainable Development Goals (SDG) places partnerships as a vital mechanism, which strengthens the implementation of change strategies. The SDG targets are ambitious; acknowledging the interconnected multifaceted issues that are currently facing society. Similarly, social marketing thought is transitioning to embrace systemic change strategies, realising no one organisation can have an impact on the emerging grand challenges. Partnerships are the 5th P in the social marketing mix, however, partnerships is also a nebulous term which has been criticised for lacking theoretical development. This study aims to answer the call from both the UN and social marketing community for further research to guide the development and implementation of impactful transformative partnerships.

Design/methodology/approach - A robust mixed method approach to develop and test a social marketing partnership model is presented. Trust and relationship commitment are at the forefront of successful partnership exchanges. Morgan and Hunt's (1994) trust and relationship commitment model is extended into the social marketing domain.

Findings - The findings validate Hasting's (2003) call for social marketers to listen to their commercial marketing counterparts, positioning trust and commitment as essential to change strategies. As the degree of complexities in the multifaceted world continues to accelerate, partnerships for change (UN SDG \#17) will pay off, driving more effective and smarter collaborations amongst a diverse range of stakeholders at different levels in different networks. Partnerships will elevate social marketing to deliver systemic transformation for

complex problems with far reaching collective and sustainable consequences.
\end{abstract}

(C) Sinead Duane, Christine Domegan and Brendan Bunting. Published by Emerald Publishing Limited. This article is published under the Creative Commons Attribution (CC BY 4.0) licence. Anyone may reproduce, distribute, translate and create derivative works of this article (for both commercial and non-commercial purposes), subject to full attribution to the original publication and authors. The full terms of this licence may be seen at http://creativecommons.org/licences/by/4.0/legalcode

The authors would like to acknowledge safefood the funders of this research, Dr Marita Hennessey and the safefood team who co-designed the Get Your Life in Gear intervention. We would also like to acknowledge and thank the Get Your Life in Gear steering group members. We would also like to thank research participants. 
JSOCM 12,1

Research limitations/implications - With trust/mistrust critical to successful exchanges and exchange central to social marketing, quantitative measurement of the antecedents to and outcomes of partnerships can inform the evaluation, impact and management of social marketing interventions.

Practical implications - Three contributions are made, which support the selection, implementation and evaluation of social marketing partnerships. Key social marketing partnership characteristics are operationalised supporting the partnership selection process. Measurement scales are developed to assist in evaluating partnership relationships over time. The model is empirically tested to investigate the relationships between key mediating variables of social marketing partnerships.

Originality/value - This paper presents a validated 5th P Partnership model for social marketers, accelerating social marketing's capacities to deliver systemic transformation for complex problems with far reaching collective and sustainable consequences and UN SDG \#17.

Keywords Structural equation modelling, Social marketing theory

Paper type Research paper

\section{Introduction}

The 17 United Nations Sustainable Development Goals (UN SDGs) provide a global agenda for change calling for urgent action through global partnerships (United Nations, 2019). This landmark blueprint accepts that the issues facing society are multifaceted, dynamic and interconnected making them hypercomplex. For example, the targets for SDG \#1 "no poverty" cannot be achieved without tackling other interrelated SDGs such as SDG \#4 "quality education" and SDG \#5 "gender inequality" issues. Multi-stakeholder partnerships across developed and developing economies are vital to achieving the ambitious SDGs targets by 2030, so much so that "partnering for the goals" has been identified as a standalone SDG \#17. Successful partnerships in this context require cross-sectoral responses, which transpose country boundaries collaborating between governments, the private sector and civil society. These inclusive partnerships are built upon the notion that "principles and values, a shared vision and shared goals that place people and the planet at the centre, are needed at the global, regional, national and local level" (UN Sustainable Development Goals, 2021). Social good, shared vision and goals are central to the UN vision for transformative partnerships, as is trust, which can be strengthened or diminished over time (United Nations, 2020).

Although viewed as a key success factor for achieving SDGs, just like the problems they are trying to address, partnership relationships can be complex and dynamic. A reflective approach is required to guide their continued development (United Nations, 2020). To support impactful multi-stakeholder partnerships, research is urgently required into the mechanisms or active ingredients for developing effective partnerships to support capacity and skills building, as well as partnership evaluation, so that collective action can manifest (ibid).

Social marketing as an approach has the potential to support the global efforts to meet SDG targets through collective action strategies. Similar to the SDGs, social marketing as a discipline places social good as the primary objective guiding all behavioural, societal and systemic change activities. Transformative and sustainable behaviour change outcomes are associated with integrated interventions, highly participatory, collaborative partnerships and trust-orientated social marketing programmes (Eagle et al., 2016). Social marketing has also positioned partnership approaches as central to change activities. Partnerships have been part of the formation of behavioural change strategies for in excess of 50 years and have even been described as the " 5 th $\mathrm{P}$ " in the social marketing mix (Donovan and Henley, 2010; Weinreich, 2011). Partnership insights have also been included as part of the definition of social marketing (Tapp and Sherif, 2013). The importance of cross-sectoral partnerships is 
further captured in the emerging macro social marketing (Biroscak et al., 2014; Brennan, 2016; Kennedy, 2016) and systems social marketing discourses (Biroscak et al., 2014; Domegan et al., 2016; Kennedy, 2016; Zürcher, 2018; Truong et al., 2019). This holistic or systems-based change approach has the potential to understand the interdependency and interconnectedness between the issues we seek to address (Flaherty et al., 2020). It also acknowledges the significant roles that stakeholders play in developing solutions when addressing collective action problems, with stakeholder engagement equating to better behavioural outcomes (Domegan, 2021; Domegan et al., 2019).

Research into the conceptual development of social marketing partnerships is lacking (Truong, 2017; Truong and Dietrich, 2018), not because it is unimportant but rather because as Hasting's (2003) mentions, partnerships are difficult to understand and manage whatever the social marketing issue being examined. Social marketing will continue to suffer if partnership development at a managerial or theoretical level does not occur, especially when faced with any one of the UN SDG (Lee, 2020). A recent critical review of the evolution of social marketing partnerships took the first steps in understanding social marketing partnerships. It found that partnership approaches have been used, as the advent of the discipline in different forms. Social marketing has continued to evolve in response to the dynamic issues it faces, as did the role of partnerships. It concluded that a definitional ambiguity surrounding social marketing partnerships remains. In the absence of a definition, partnerships can be conceptualised by examining the key characteristics common across three eras of social marketing development, from a transactional to formalisation to an integrated systems approach (Duane and Domegan, 2019). Key characteristics include shared interest/value, sharing of resources (tangible and intangible), formal agreement, prioritisation of partners and trust and commitment. However, the relationships between these characteristics has never been empirically tested (ibid).

The overall aim of this paper is to develop and empirically test a social marketing partnership model to scale up collective action. This research answers the UN call for further exploration into strategies to support the development of mechanisms and platforms to revitalise global partnerships. For the first time from a social marketing perspective, a theoretical model for the development and maintenance of social marketing partnerships is discussed. This research contributes to:

- the operationalising of social marketing partnership constructs, which can be used to support the partnership selection process;

- the development of social marketing partnership scales, which could be used to evaluate existing multi-stakeholder partnership relationships and guide their long term implementation;

- empirically test the proposed social marketing partnership model to deepen our understanding of the dynamic interactions between the key characteristics of social marketing partnerships. This knowledge supports the development of mechanisms to improve the efficiency of partnership selection and maintenance activities; and

- identifying the active ingredients to support capacity and skills building to foster collective action.

This paper begins by discussing how relational thinking guided the theoretical development of the first social marketing partnership model. The latter half of this paper introduces the model building and testing process, followed by a discussion on how this knowledge can help achieve UN SDGs targets and accelerate the scaling up of change activities. 
JSOCM

12,1

\section{Relational thinking for social marketing partnerships}

The centralised role of partnerships is undisputed however, the theoretical development of it is lacking (Duane and Domegan, 2019; Hastings, 2003). Marketing exchange as a defining characteristic within social marketing (Hastings and Saren, 2003) can be used to illustrate the important role of relational thinking in twenty-first century partnership development. Whilst it is beyond the scope of this article to discuss the role of exchange theory in detail, which is discussed elsewhere (Duane et al., 2016), it is important to introduce the notion of "complex exchange", which reflects the type of partnership approaches needed to address the SDGs.

The type of multilevel, cross-sectoral partnerships needed to meet SDG targets are beyond simple restricted exchange activities that were traditionally built on short term, discrete transactions (Domegan et al., 2019). Instead, transformative partnerships manifest as complex exchanges that are defined as "a system of mutual relationships between at least three parties” (Bagozzi, 1975 p. 33). Complex exchanges represent webs or networks of exchanges between multiple parties and can be direct and indirect usually developing over time (Duane et al., 2016). Time is important to social marketers as there is usually a delay between the return on investment in these high involvement exchanges as the impact of partnership activities is not instant (Hastings and Saren, 2003). The presence of time permits the development of trusting relationships as it allows partners to observe each other's responses to issues as they arise. For instance, is engagement maintained or do tensions manifest (Domegan et al., 2019)? Trust underlines effective partnerships in social marketing (Lefebvre, 2012) and is central to the development of any social marketing programme (Hastings, 2003). The non-profit nature of social marketing places trust as central to social marketing relationships (Hastings, 2003) where society is the focus of benefit and not the shareholder (Lefebvre, 2012). Trust is central to the development of any long-term relationships as trust should increase over time (Johansson et al., 2018). Time is a critical factor that transitions trust into commitment (ibid). Commitment and trust are thought to be greater amongst parties whom do not receive monetary rewards for their activities (Hastings and Saren, 2003). Trust also manifests as reliability and dependency over time, reinforcing the notion of certainty within change relationships (Baloch et al., 2020). Trust has also been described as a value, the impact of which spans beyond interpersonal relationships, a trait that prevents stakeholders from losing confidence in change activities (Lefebvre, 2012). This is important when addressing highly complex multifaceted issues. If there is no trust or commitment, the motivation to continue a relationship diminishes (Singer and Kayson, 2004). Trust and commitment allow for a working relationship to manifest in the presence of different sectors, different values or marketing systems (Choi et al., 2007). This type of cross-sectoral transfer impacts on the level of trust, and therefore, commitment because it also introduces new types of transactions (Andreasen, 2001).

As social marketers continue to adopt systemic change activities built on complex exchange systems, there is a renewed recognition of the role of relational thinking and associated partnership constructs in social marketing. Hastings (2003) was one of the first social marketers to recognise the potential of relational thinking for the discipline. This expanded approach recognises mutual beneficial relationships as an important consideration when dealing with high involvement multifaceted issues (Hastings, 2003). This perspective positions trust and commitment at the core of developing long-term relationships, particularly in the non-profit environment. Relational thinking promotes partnership development through the identification of motivational opportunities because of the presence of trust (Gordon, 2013). It is built on the premise of customer satisfaction that again transitions from a short term to a longer-term sustainable orientation. In addition, 
Brennan et al. (2016 p. 232) propose six key social marketing characteristics that highlight the appropriateness of relational thought in social marketing:

- the absence of the profit motive;

- the focus on high-involvement decisions;

Social marketing partnership model

- complex and multifaceted behaviours;

- changes that take a long time;

- the relevance of trust; and

- the need to target the most needy and hard-to-reach groups in society.

As described above, the complex and high involvement nature of social marketing asserts that characteristics such as trust and commitment must be present to move beyond once off transactions into longer-term relationships. To meet SDG targets, social marketers need to transpose sector, organisations and communications with trust and commitment becoming the foundations of cooperative working.

There is an opportunity to extend Morgan and Hunt's (1994) relationship commitment and trust model into the social marketing domain to improve our understanding of how to establish, develop and maintain partnerships when dealing with complex exchange activities. Morgan and Hunt's (1994) model is one of the best-known relationships marketing theories guiding the development of long term cooperative behaviours in the commercial context (Figure 1). Trust and relationship commitment were conceptualised as being central constructs in the seminal Morgan and Hunt's relational model (Morgan and Hunt, 1994). They hypothesize that key mediating variables (antecedents and outcomes) have a positive or negative impact on the central constructs and this conceptualisation can help select partners and evaluate partnership performance.

This model represented a paradigm shift within traditional marketing theory. It marked a transition from a transactional perspective to a relational network paradigm that attributes interrelationships and cooperation as key to competing in hyper-competitive

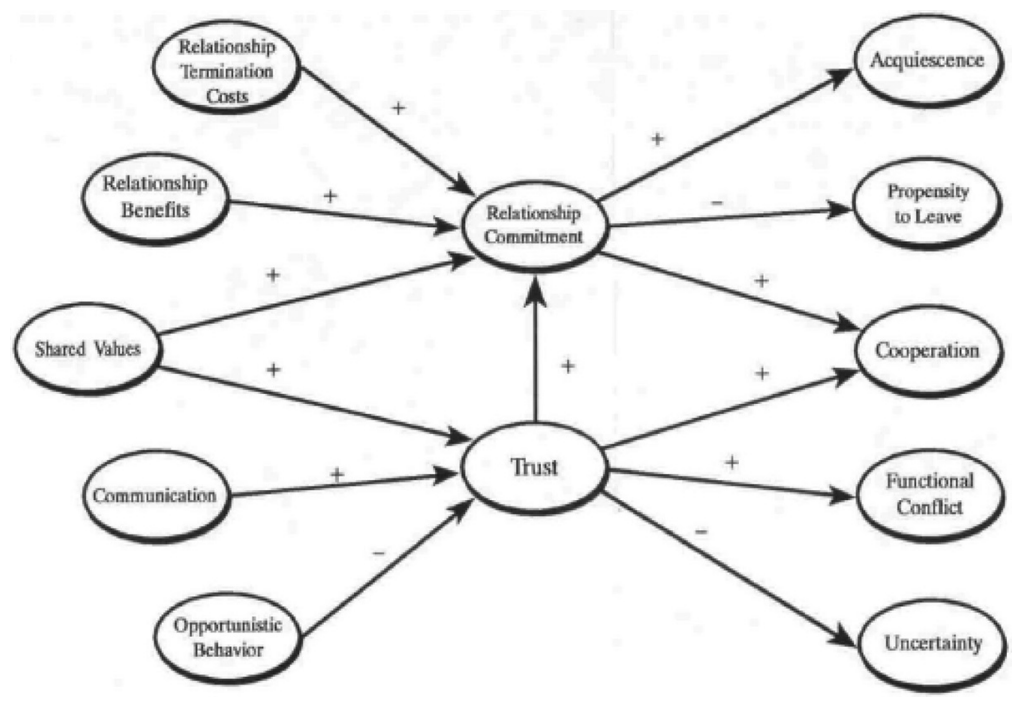

Figure 1. Morgan and Hunt's (KMV) model of relationship 
JSOCM

12,1

marketplaces (Morgan and Hunt, 1994). This relationship marketing orientation moves beyond the selling of core products to understanding the value of interactions, relationships and networks (Gummesson, 1994). As discussed, a similar transformation is underway within social marketing, moving from traditionally restricted exchange orientations to a complex one to address the multifaceted systemic issues that are currently facing our societies. Taking any of the 17 SDGs as an example; \#1 no poverty, \#2 zero hunger, \#4 quality education, \#14 life below water, it becomes clear that these issues transcend societies, borders and marketing systems. No one organisation can successfully address these issues thereby networks, interactions and relationships become critical for success.

Morgan and Hunt's (1994) model has been tested in many different contexts and settings including the non-profit sector (MacMillan et al., 2005). For the first time, it is extended into the social marketing domain. The remainder of this paper will discuss this process. Key constructs of social marketing partnerships will be identified and operationalised using social marketing literature, a longitudinal case study analysis and expert in-depth interviews. The relationships between constructs is subsequently hypothesized and empirically tested with social marketing experts. This paper will conclude with a discussion on how this model can assist the UN to meet SDG targets in the future.

\section{Extending Morgan and Hunt's relational model into social marketing}

Using Morgan and Hunt's (1994) approach for guidance, a rigorous mixed method process was undertaken to extend and empirically test Morgan and Hunt's (1994) model into the social marketing domain. The first step, a critical review of the social marketing literature, identified if the key constructs validated in the commercial context existed in a social marketing domain. The critical review mapped the theoretical and conceptual evolution of partnerships since the conception of social marketing. Constructs that support successful social marketing partnership development were identified including shared interest/value, sharing of resources (tangible and intangible), formal agreement, prioritisation of partners, trust and commitment. A disconnect between the application of social marketing partnerships and its theoretical development was also illustrated (Duane and Domegan, 2019).

An explanatory case study was undertaken to build the hypothesized model and pre-test the social marketing constructs (Hunt, 2010a, 2010b). Case study analysis allowed for the examination of the constructs of social marketing partnerships in a real life context prior to model testing (Platt, 2006). The case study also operationalised construct definitions and supported scale development. Data for the case study was collected across two and a half years of the development of a workplace social marketing initiative funded by a government agency. Unlike the critical review, this process allowed for the examination of the relationships between constructs. This process assisted with predicting and explaining how partnership relationships manifest before determining a theory (Sutton and Staw, 1995). The case study design also supported the intersubjective reliability of key constructs by helping to establish operational definitions. The final key social marketing partnership constructs were then modelled as key mediating variables and research hypotheses.

Finally, the model was empirically tested through an online quantitative survey with behavioural change experts. Social marketing is a small but growing community. Experts whose organisations had engaged in partnership activities and whose work engaged with five of the eight benchmark criteria were invited to undertake the survey. Experts were invited to respond to the survey as representatives of their organisation. The survey was distributed online through social marketing networks. The next section discusses the 
operationalised definitions for the social marketing partnership constructs and presents the hypothesized social marketing partnership model.

\section{Social marketing partnership key mediating variables \\ Trust and relationship commitment}

As the role of trust and commitment have been justified, the discussion will focus on the operationalised definition for these constructs. Morgan and Hunt (1994) conceptualised trust as "when one party has confidence in an exchange partner's reliability and integrity" (Morgan and Hunt, 1994, p. 23). This definition of trust was too commercially orientated and did not reflect the value orientation of trust within social marketing. MacMillan et al. (2005) believed that trust was defined through the sub-constructs reliability, dependability and faith (MacMillan et al., 2005). These attributes are also supported in the social marketing domain. The case analysis identified that the concept of trust was associated with characteristics such as reliability and predictability. When the trust was eroded, the commitment levels within the partnership were questioned; if the trust was high the perceived level of commitment was as well.

Commitment manifests over time in the presence of trust. Morgan and Hunt define relationship commitment as "an exchange partner believing that an ongoing relationship with another is so important as to warrant maximum efforts at maintaining it; that is, the committed party believes the relationship is worth working on to ensure that it endures indefinitely" (Morgan and Hunt, 1994, p. 23). This definition was reflective of how relationship commitment was perceived within social marketing, and therefore, accepted.

\section{Antecedents of commitment and trust}

In the social marketing model, there are only three antecedent variables; mutual benefits, shared values and communication. Opportunistic behaviour and relationship termination costs were not supported in the literature and so are not discussed within. Relationship benefit was modified to become mutual benefits.

Mutual benefit. Morgan and Hunt's (1994) economic dependence construct (relationship benefits), which measures the switching costs of partners was not supported by the social marketing literature. MacMillan et al. (2005) also rejected relationship benefits replacing it with nonmaterial benefits. Within the social marketing context, nonmaterial benefits is also deemed unsuitable. Nonmaterial benefits does not account for the tangible and intangible exchanges that manifest through multifaceted social marketing partnerships. Therefore, the construct was modified to become a mutual benefit. Mutual benefit is an important construct within social marketing relational exchanges because of the non-profit nature of activities and delay in behavioural delay outcomes (Hastings and Saren, 2003). The type of knowledge transfer that Andreasen (2001) introduces is identified to be reciprocal, meaning that it penetrates deep within the relationship. Therefore, mutual benefit is operationalised as reciprocity and complementary resources. This definition is supported in the wider marketing literature whereby organisations achieve added value within cooperative relationships by eliminating deficiencies in their capabilities by the sharing of resources to achieve their organisational goals (Lambe et al., 2002). Due to the non-profit nature of social marketing, stakeholders might not have all the resources and capabilities to catalyse change, through mutual benefit activities are stronger as resource deficits are reduced. This type of sharing of resources only positively manifests when the organisation is committed to the relationship and can benefit from it. For example, the partnership assists in meeting goals within the social change market place. This was reinforced within the case study as every partner benefited either tangibly or intangible from the partnership. When partners 
JSOCM

12,1

failed to benefit from the partnership, their commitment decreased. Complementary resources are identified as an appropriate means of measuring this construct as it captured both tangible and intangible benefits. Complementary resources are defined as an organisation's ability to eliminate deficiencies in their capabilities by the sharing of resources to achieve their organisational goals (Lambe et al., 2002):

H1. There is a positive relationship between mutual benefit and commitment.

Shared values. Morgan and Hunt's (1994) definition of shared values is accepted, and therefore, conceptualised as "the extent to which partners have beliefs in common about what behaviours, goals and policies are important or unimportant, appropriate or inappropriate and right or wrong” (Morgan and Hunt, 1994 p. 25). This is the only antecedent that is directly connected to both commitment and trust. Shared values is identified as one of the most essential elements for social marketing partnerships to achieve high impact (Crutchfield and Mc Leod Grant, 2008). The sharing of values positively equates to goal convergence, which is directly related to the presence of trust (Legarde et al., 2005). Similarly, the presence of shared values is a precursor of commitment as it reduces the presence of tension, which erodes trust, and therefore, has an impact on commitment. This assertion was further emphasised within the case study. When goal convergence and shared values existed, partners adopted a similar approach to problem-solving. This had a positive impact on both trust and commitment:

H2. There is a positive relationship between shared values and relationship commitment.

H3. There is a positive relationship between shared values and trust.

\section{Communication}

Morgan and Hunt conceptualised communication using Anderson and Narus's (1990) definition, "the formal, as well as informal sharing of meaningful and timely information between firms" (Anderson and Narus, 1990, p. 44). MacMillan et al. (2005) argued that Morgan and Hunt's (1994) items did not appraise communication as a two-way process. Within social marketing, communication often encompasses both communications across and between levels of the partnership, and therefore, reaffirming it as a two-way process. MacMillan et al. (2005, p. 816) extended their interpretation of communication to include "informing, listening and staff interactions" reflecting the two-way approach to communication within funder relationships. These facets of communication were not supported within the social marketing partnership context. Communication has a positive relationship with trust, however; poor communication within partnerships unnecessarily diminishes the level of trust within a partnership. Trust is enhanced when, for example, the expectations, roles and responsibilities are explicitly stated (Legarde et al., 2005). Stakeholders within a social marketing partnership may have different perspectives of an issue and communication is key to understanding these perspectives when developing collective responses (Wymer, 2021). The case study supported the identification of communication as a powerful construct, which has a positive relationship with trust. When partners communicated poorly, trust was diminished. Frequency and formality of communications in the early stages of the partnership increased levels of trust. The type of communication also depended on the maturity of the relationship. In response to diminished levels of trust, effective communication was also used to rebuild the relationship. 
Therefore, communication is operationalised as information sharing, quality and participation as defined by Mohr and Spekman (1994):

H4. There is a positive relationship between communication and trust.

\section{Social marketing partnership model}

\section{Outcome of commitment and trust}

Three outcome variables were included; expectation of continuance, cooperation and tension. Propensity to leave was replaced as an outcome variable by expectations of continuance or motivation and functional conflict was modified to become tension. Acquiescence and uncertainty were not supported within the social marketing literature.

\section{Expectation of continuance (motivation)}

Morgan and Hunt's (1994) construct opportunistic behaviour was not supported due to the non-monetary nature of social marketing relationships. Instead, continuity of expectations or motivation was identified as an outcome of commitment. Continuity of expectations encompassed motivation to continue the relationship for the sustainability of long-term partnerships. Motivation in a social marketing partnership is related to self-interest in the endeavour, which turns short term relationships to long-term partnerships and is, therefore, directly related to commitment. The case study suggested that expectations of continuance was positively associated with relationship commitment and referred to the likelihood partners would continue the relationship in the future:

H5. There is a positive relationship between relationship commitment and expectation of continuance.

\section{Cooperation}

Morgan and Hunt (1994) suggest that cooperation is a positive outcome of both commitment and trust. Cooperation is symbolised by the sharing of tangible and intangible resources and is identified as a direct positive outcome of commitment and trusting relationships. Cooperation manifests when parties work together to achieve mutual goals (Anderson and Narus, 1990; Morgan and Hunt, 1994). In social marketing, this perspective encompasses knowledge-sharing, value adding expertise and expectations of brand leveraging (Lee et al., 2005). Within the case study, high levels of commitment and trust resulted in more proactive cooperation between partners. The sharing of tangible and intangible resources was seen as symbols of positive cooperative behaviours:

H6. There is a positive relationship between relationship commitment and cooperation.

H7. There is a positive relationship between trust and cooperation.

\section{Tension}

Conflict as measured by Morgan and Hunt (1994) was represented as a negative outcome of trust. The conflict has not emerged as a key characteristic in the social marketing literature. However, tension did manifest leading to the modification of this construct. Negative behaviours on the part of any member of the partnership could have a negative impact on the behavioural change strategy (Bhattacharya and Bell, 1999). Negativity manifests in social marketing relationships as tension, which directly erodes the level of trust within the relationship (Thomas, 2008). Within the case study, tension arose when partners were 
JSOCM

12,1

\section{8}

Figure 2.

Proposed key mediating variable model of social marketing partnerships perceived as unreliable or unpredictable. Communication could be used to reduce levels of tension, however, only when the trust was perceived to be high:

H8. There is a negative relationship between trust and tension.

Figure 2 presents the hypothesized social marketing partnerships measurement model.

\section{Model testing}

Survey development

Self-reported measures were used and each item captured the domain of each construct (Churchill, 1979). The authors followed Beraden et al. (2011) scale selection criteria. Three scales were adopted from Morgan and Hunt (1994) and two from MacMillan et al.'s (2005) extension of their model into the non-profit context. The remainder were adapted from marketing literature. The supplementary file includes a copy of the full scales used, sources and the reported validity and reliability measures. All chosen scales were continuous to fulfill the requirements of AMOS (Byrne, 2001).

Construct validity was enhanced as each scale was comprising multiple items (Baumgartner and Homburg, 1996; Hair et al., 2006). Dimensionality of the scales were assessed through exploratory factor analysis (EFA) where a large number of items were included. Unidimensional constructs were aggregated to form composites and analysed as a single indicator (Baumgartner and Homburg, 1996). Table 1 summarises the construct and reported validity and reliability measures.

Prior to the launch of the survey, eight social marketing experts, three academic and five social marketing practitioners, were invited to pre-test the survey. Dillman's cognitive interviewing technique (face-to-face) or Dillman's retrospective technique (online) were adopted to ensure face and construct validity. Experts were requested to read aloud the survey and express their views on the survey as they completed it (Dillman, 2000). The relevance, understanding and order of scales were also discussed. All experts held management positions and had worked on major social marketing campaigns in Ireland or the UK. Two statisticians were also invited to assess the scales from a methodological and analytical perspective. Minor amendments were made to the terminology used in the screening questions and a definition of social marketing partnerships was included at the

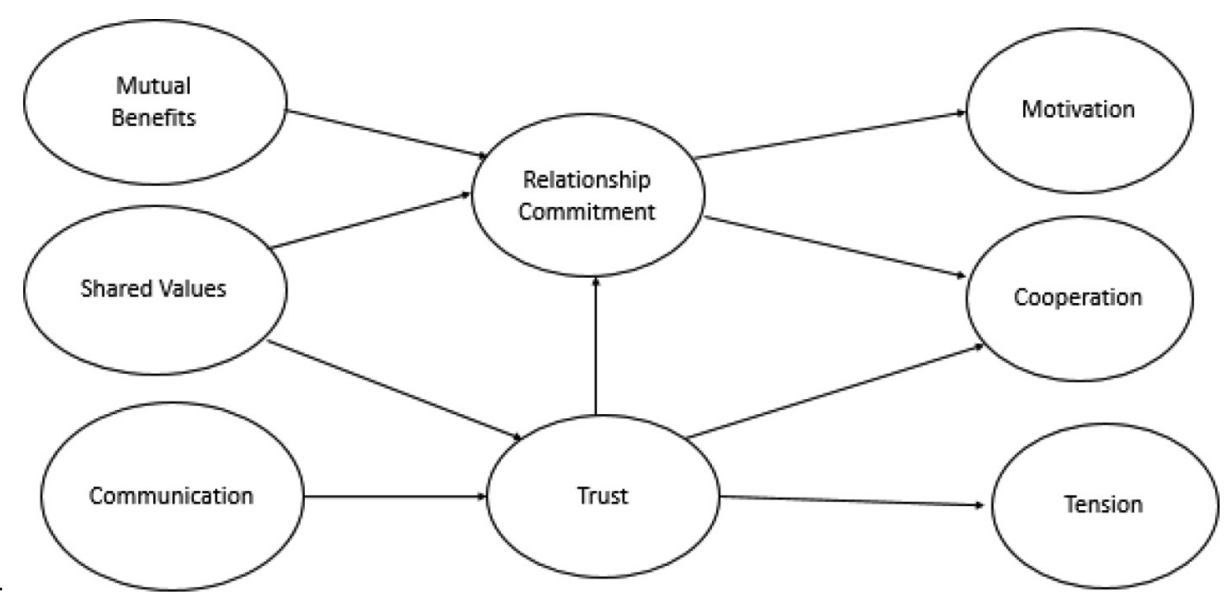




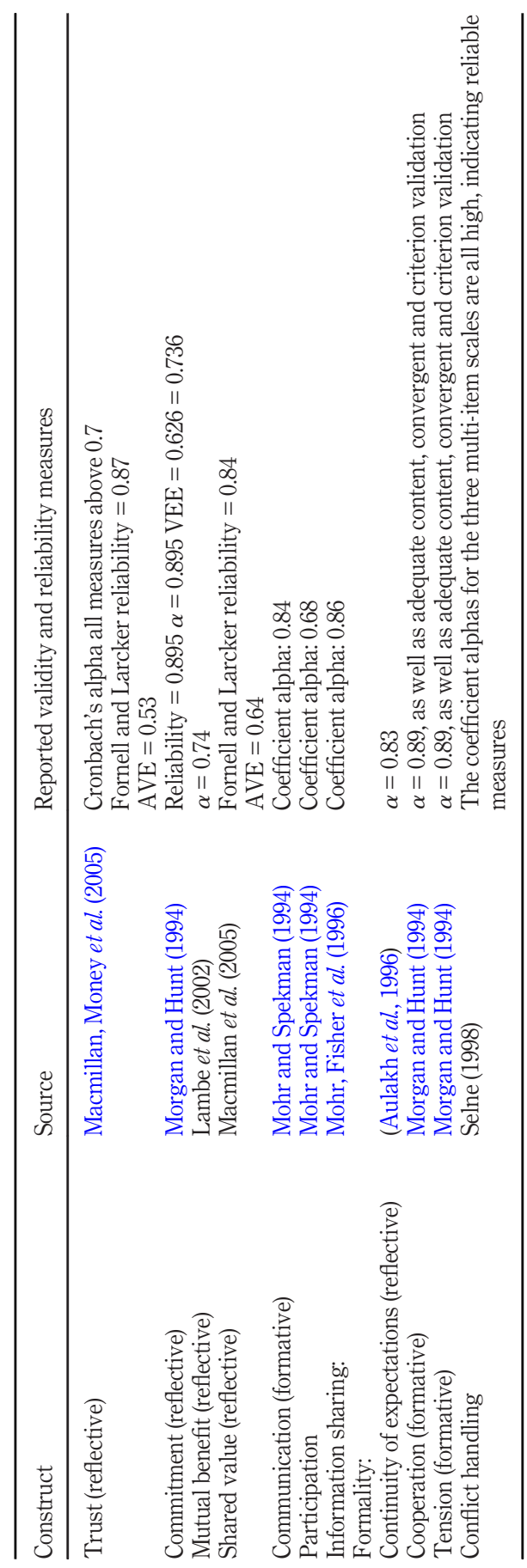

Social marketing partnership model

59

Table 1

Summary of constructs and 
JSOCM

12,1

60 beginning of the survey. Furthermore, the instructions for the survey were modified to ensure that participants answered the questions in respect to the one partner they interacted with the most.

All the survey participants stated that they had participated in behavioural change partnerships in the past five years. They were subsequently asked a series of questions relating to their organisation's level of participation, knowledge, involvement and maturity of this behavioural change partnership.

Data analysis. To confirm the validity of the proposed social marketing partnership model, the internal logic of the research hypothesis were scrutinised (Hunt, 2010b). A twostep approach to structural equation modelling was adopted allowing the researcher to make "meaningful inferences about the theoretical constructs and their interrelations" (Anderson and Gerbing, 1988, p. 411). Firstly, EFA was conducted.

Exploratory factor analysis. EFA defined the dimensions of the data and determined the degree to which each variable was explained by the underlying dimension (Ghauri and Gronhaug, 2010). EFA created summated scales as a data reduction technique (Hair et al., 2006). A maximum likelihood technique was used to assess the reflective items (relationship commitment, trust, mutual benefit, shared value and expectation of continuance). A principle components technique was used to interpret the dimensionality of the formative item scales (cooperation, communication and tension). It was also used to determine, which item or items contributed the most information to each component and resulted in the reduction of the number of items into fewer principle components (Hair et al., 2006). When assessing formative or reflective item scales, a loading of 0.4 was acceptable (ibid).

Confirmatory factor analysis. Confirmatory factor analysis tested the measurement model and assessed how well the measured items represented the constructs and the relationship or correlations between them (Hair et al., 2006). Accurate specification was a core requirement prior to the analysis of the structural model (Jarvis et al., 2003; Anderson and Gerbing, 1988). AMOS version 18 was chosen to commute the results. Seven guided the assessment of univariate normality. A critical ratio value of $>5$ was indicative of nonnormally distributed data. Mahalanobis d-squared test was undertaken to detect univariate and multivariate outliers. Outliers were present when the scores from the Likert scales were different from the other respondents.

Model fit indices. After the model was specified the goodness of fit was assessed (Hu and Bentler, 1999). There is little consensus of how to choose the most appropriate goodness of fit statistics (Byrne, 2010; Hooper et al., 2010). Goodness of fit indices, which were used to evaluate the model included; $x^{2}(>0.05)$, root mean square error of approximation (RMSEA $(<0.05)$, Goodness of fit, Adjusted goodness of fit, Tucker lewis index (all values close to 1) and Comparative fit index (values close to 0.9).

The measurement model: reliability and validity. Coefficient alpha assessed reliability (Ping, 2004) and convergence, the measure of reliability for this estimate is 0.7 or higher (Hair et al., 2006). Construct validity considers the factor loadings and can be measured by an evaluation of maximum likelihood estimates. Statistically significant factor loadings and standardised loading estimates were accepted if 0.5 or higher and ideally 0.7 or higher (Hair et al., 2006; Shook et al., 2004; Fornell and Larcker, 1981). In total, 70\% was the upper limit for the reliability of a construct whilst variance-extracted measures should equal or exceed $50 \%$ (Hair et al., 2006).

The variance extracted percentages for any two constructs was compared with the squared estimates between them identifying that the construct adequately explains its item measures. 


\section{Findings}

Participant characteristics

In total, 90 participants initiated the survey of which 36 participants were excluded from analysis as surveys were incomplete $(n=17)$ or participants did not fulfil inclusion criteria $(n=19)$. Data from 54 surveys were analysed. The majority of participants worked in the Republic of Ireland $(n=20)$ or UK $(n=24)$. In total, 49 participants worked with organisations who had implemented behavioural change strategies for three of more years. A profile of the survey participant characteristics is provided in Table 2.

Participants were asked to identify the behavioural change area in which they worked. A summary of the areas in which partnerships were being formed is provided in Figure 3. The majority of participants were working on public health issues.

\begin{tabular}{ll}
\hline Characteristic & Frequency $(n)$ \\
\hline $\begin{array}{l}\text { Participated in social marketing partnership activities in the past five years } \\
\text { Level of knowledge of partnership }\end{array}$ & All \\
& Very knowledgeable $=21$ \\
& Knowledgeable $=28$ \\
Maturity of partnership & Not knowledgeable $=4$ \\
& Neutral $=1$ \\
& Very mature $=9$ \\
& Mature $=29$ \\
Involvement & Somewhat mature $=12$ \\
& Immature $=3$ \\
& Very immature $=1$ \\
Received formal training in social marketing? & Highly involved $=26$ \\
& Involved $=20$ \\
& Involved to a degree $=7$ \\
& Not at all $=1$ \\
& Yes $54 \%$ \\
& No $43 \%$ \\
& Undisclosed $3 \%$
\end{tabular}

Table 2.

Summary of participant characteristics

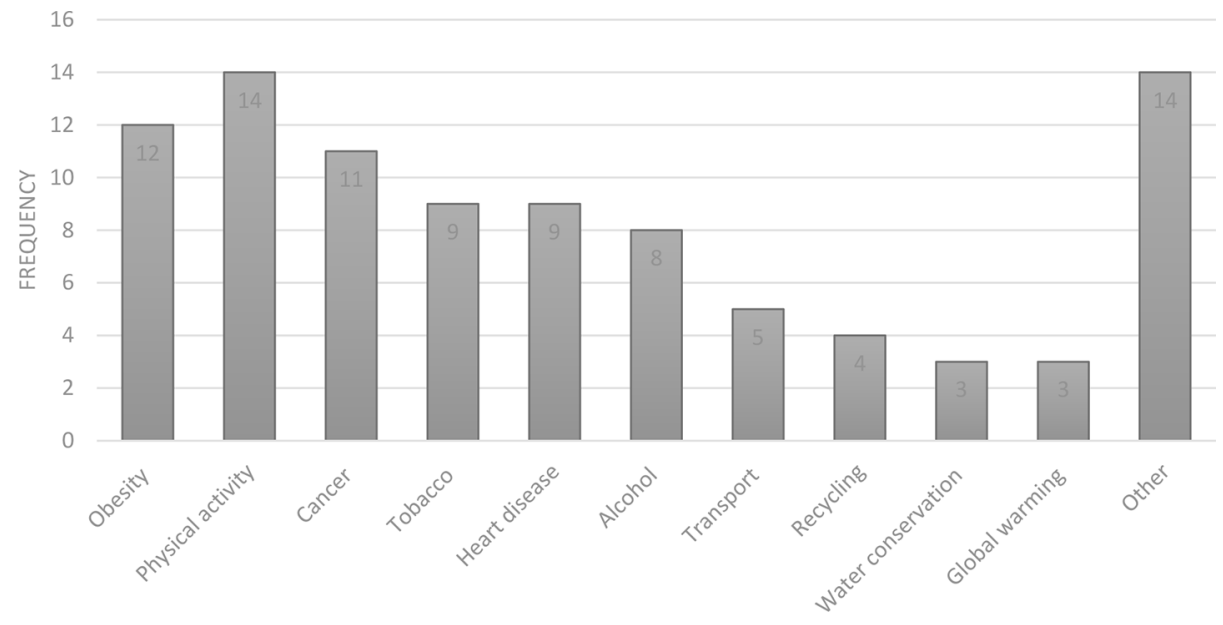

Figure 3. Summary of social marketing issues 
JSOCM

12,1

62

\section{Exploratory factor analysis}

Three constructs had multidimensional factors (trust, communication and tension), the remainder were unidimensional loading with one score. Additional labels were assigned to the multidimensional constructs. Table 3 provides a summary.

\section{Trust}

The trust reflexive item scale loaded on two factors, which were subsequently relabelled. All factor loadings for the trust had a significance level above \pm 0.5 with the exception of one. It was not deemed necessary to delete this item from the scale.

Three trust items loaded to Factor 1, which was relabelled as reliability. The item that loaded the strongest (0.999) assessed the future of partnerships in times of uncertainty. The other two items measured the dependability and credibility of the partner. Two additional item scales loaded to a second factor labelled as predictability.

\section{Communication}

In total, 14 items within the communication scale loaded significantly across three components (expectations (comm_1), information sharing (comm_2) and type of information (comm_3)).

\section{Cooperation}

In total, 17 items in the cooperation scale loaded on 4 principle components. In total, 15 of the items were loaded on component one, one item loaded on component 3 and one item on component 4. Only one component was shown to represent cooperation and remained labelled as cooperation.

\section{Tension}

The 16 tension items loaded across two components relabelled as "causes of tension" and "tension handling". All the statements that loaded on "causes of tension" were all highly significant above 0.6 with the exception of branding, which was still significant at 0.555 . The remainder of statements loaded on "tension handling".

Measurement model. Figure 4 illustrates the measurement model. Resulting from the EFA the model contained 25 variables (15 endogenous and 10 exogenous) and 11

\begin{tabular}{llcll}
\hline Construct & Technique adopted & No. of factors & Loaded with & Label \\
\hline $\begin{array}{l}\text { Relationship } \\
\text { commitment }\end{array}$ & Maximum likelihood & 1 & RC_FS & \\
Trust & Maximum likelihood & 2 & Tr_1 $\rightarrow$ & Reliability \\
Mutual benefit & Maximum likelihood & 1 & Tr_2 $\rightarrow$ & Predictability \\
$\begin{array}{l}\text { Shared values } \\
\text { Communication }\end{array}$ & Maximum likelihood & 1 & SV_FS & \\
& Principle component & 4 & Comm_1 $\rightarrow$ & Expectations \\
& & & Comm_2 $\rightarrow$ & Information sharing \\
Expectation of & Maximum likelihood & 2 & Comm_3 $\rightarrow$ & Type of information \\
continuance & Mov_FS & \\
$\begin{array}{l}\text { Cooperation } \\
\text { Tension }\end{array}$ & Principle component & 1 & Coop_1 & \\
& Principle component & 3 & Ten_1 $\rightarrow$ & Strategic direction \\
& & & Ten_2, $\rightarrow$ & Tension handling \\
\hline
\end{tabular}

Table 3.

Summary of factor loadings and components with labels
Cooperation 


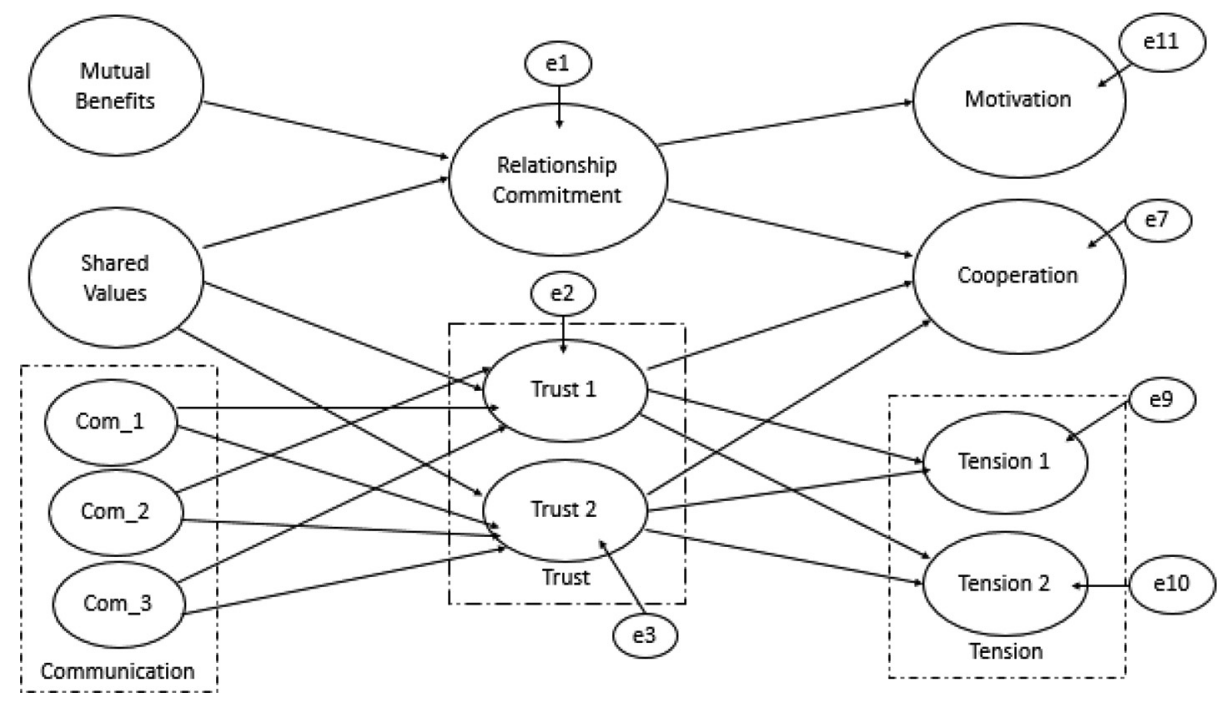

Social marketing partnership model

63

unobservable, which were specified. These unobserved variables account for information that is not contained in the model and are labelled from e1 - e11. To differentiate between the unidimensional and multidimensional variables, the factors or summated scales are presented separately within the model. For example, the multidimensional latent variable trust is represented as Trusts 1 and 2.

\section{Confirmatory factor analysis}

No item was shown to be substantially kurtomic. Mutual benefit exceeded 7 with a measure of 7.7682. However, this was not considered to be extreme (Byrne, 2001). The Mahalanobis d-squared test showed minimal evidence of serious multivariate outliers, meaning the scores within the items scales remained similar.

\section{Goodness of fit}

The chi-square goodness of fit (139.21) does not approximate the degrees of freedom (36); indicating an inadequate model fit. CFI (0.36) is low and far away from 0.95, suggesting that significant amounts of variance remain to be explained (Bagozzi and Foxall, 1996). Similarly, the TIL $(-0.178)$ is not greater than 0.95 as required. The RMSEA is below the recommended $0.05(0.23)$, which is indicative of a good model fit, however, the other goodness of fit indices do not support the specification of this model.

The data does not reasonably fit with the model, and therefore, requires re-specification. Before the model was re-specified the maximum likelihood loadings were assessed for model fit. The crucial ratio value was greater than 5 (6.47). Therefore, caution must be taken when interpreting the maximum likelihood distribution (Bentler and Yuan, 1999).

The maximum likelihood regression weights presented in Table 2 suggest that 6 of 29 proposed relationships in the measurement model are statistically significant. One more is significant at the $10 \%$ level (1.69), which is acceptable given the small sample size. These relationships have been highlighted in bold. Statistical significance was assessed with a critical ratio greater than 1.96 and a $P$-value less than 0.1 . 
JSOCM

12,1

64

\section{Model re-specification}

The decisions to implement the prescribed modifications were based on statistical analysis and underlying theory. Modification indices (MI) guided the re-specification process as large MI's ( $>10)$ argue for cross-loadings and error covariance's. However, changes were only made if they were supported by theory. Table 5 summarises the re-specification process. Five modifications were implemented.

The path diagram for the final re-specified model is shown in Figure 5. The first respecification introduced a direct path from comm_1 (expectations) to cooperation. This path was not hypothesized as trust was thought to be a mediating variable for cooperation. As a result of the EFA, expectations became one dimension of communication. When expectations are not met, trust diminishes, which results in diminished cooperation. Cooperative behaviours call for an interdependence between parties that is ultimately aligned with the management of expectations, through a willingness to share tangible and intangible resources. With careful communication of expectations between partners, the cooperative behaviours should be apparent, and therefore, diminishes the need for a direct path between trust. Therefore, this modification was accepted. This modification improved fit by reducing the chi-square from 139.22 to 99.61 bringing it closer to the degrees of freedom $(\mathrm{df}=36)$. There was also an improvement within the other goodness of fit statistics particularly the CFI.

A direct path from shared values to cooperation was created. Within the literature, the concept of shared values was emphasised. Organisations whose goals converged or shared similar values had a pre-established level of trust, for example, Legarde, Doner et al. (2005) suggested that similar entities such as non government organisation have a greater goal convergence. These shared values, therefore, would be linked with a willingness to share resources. This path also had a positive effect on all the goodness of fit statistics.

The inclusion of direct paths between comm_1 (expectations) and cooperation; and shared values and cooperation, were the only two modifications that had the power to produce a significant effect on the model fit. As shown in Table 4, three additional

\section{Figure 5.}

Re-specified social marketing partnership model

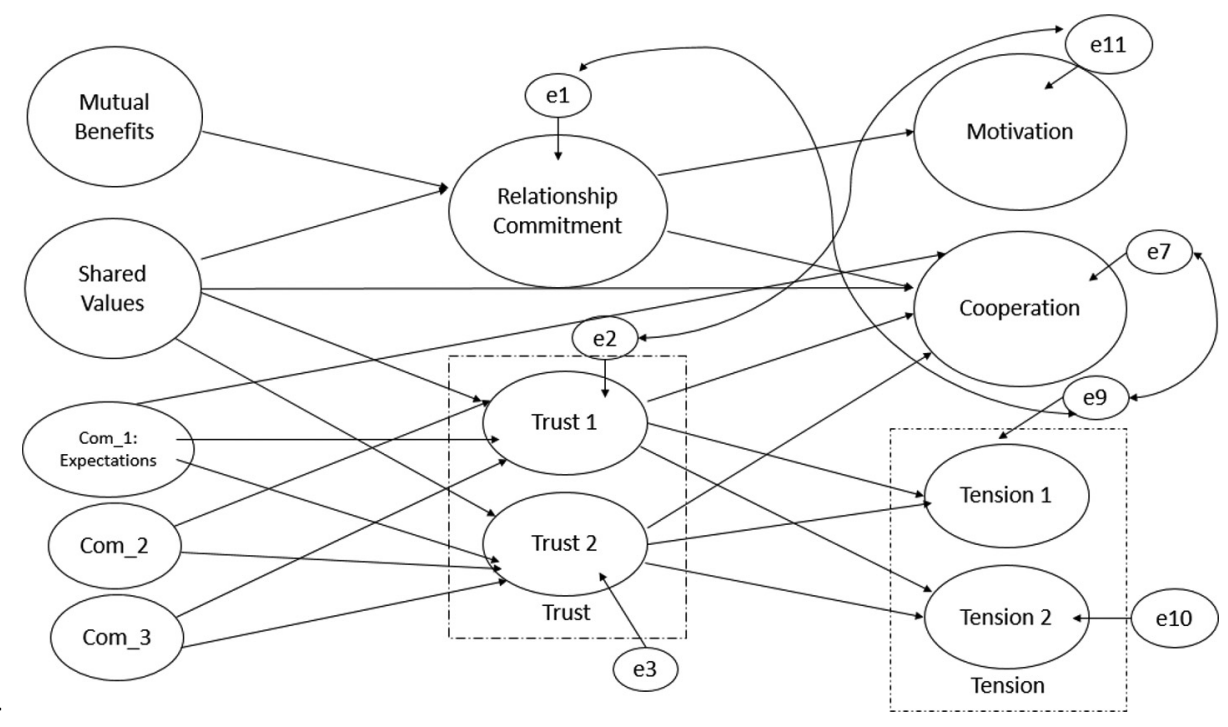




\begin{tabular}{|c|c|c|c|c|c|c|c|}
\hline \multicolumn{3}{|c|}{ Components } & \multirow{2}{*}{$\begin{array}{r}\text { Estimate } \\
0.0586\end{array}$} & \multirow{2}{*}{$\frac{\text { S.E. }}{0.1527}$} & \multirow{2}{*}{$\frac{\text { C.R. }}{0.3835}$} & \multirow{2}{*}{$\frac{P}{0.7014}$} & \multirow{3}{*}{$\begin{array}{r}\text { Social } \\
\text { marketing } \\
\text { partnership }\end{array}$} \\
\hline Tr_1 & $<-$ & SV_FS & & & & & \\
\hline Tr_2 & $<-$ & SV_FS & -0.1431 & 0.1296 & -1.1039 & 0.2696 & \\
\hline $\operatorname{Tr} \_1$ & $<-$ & Comm 1 & -0.0140 & 0.1507 & -0.0927 & 0.9262 & \\
\hline $\operatorname{Tr} 2$ & $<-$ & Comm 1 & 0.5675 & 0.1279 & 4.4360 & $* * *$ & \\
\hline Tr_1 & $<-$ & Comm_2 & 0.0979 & 0.1371 & 0.7135 & 0.4755 & \\
\hline Tr_2 & $<-$ & Comm_2 & -0.0708 & 0.1164 & -0.6078 & 0.5433 & 65 \\
\hline $\operatorname{Tr} 1$ & $<-$ & Comm 3 & -0.0142 & 0.1379 & -0.1026 & 0.9183 & \\
\hline Tr_2 & $<-$ & Comm_3 & -0.1203 & 0.1171 & -1.0275 & 0.3042 & \\
\hline RC_FS & $<-$ & MB_FS & -0.0694 & 0.1305 & -0.5314 & 0.5952 & \\
\hline $\mathrm{RC} F \mathrm{FS}$ & $<-$ & $\operatorname{Tr} \_1$ & -0.0050 & 0.1186 & -0.0422 & 0.9663 & \\
\hline RC_FS & $<-$ & Tr_2 & 0.2046 & 0.1210 & 1.6916 & 0.0907 & \\
\hline RC_FS & $<-$ & SV_FS & 0.3247 & 0.1268 & 2.5604 & 0.0105 & \\
\hline Coop_1 & $<-$ & RC_FS & 0.1232 & 0.1311 & 0.9400 & 0.3472 & \\
\hline Coop_1 & $<-$ & Tr_1 & -0.1243 & 0.1200 & -1.0357 & 0.3003 & \\
\hline Coop_1 & $<-$ & Tr_2 & $\begin{array}{r}-1243 \\
0.4328\end{array}$ & 0.1237 & 3.4977 & $* * *$ & \\
\hline Ten_2 & $<-$ & Tr_1 & -0.0320 & 0.1323 & -0.2417 & 0.8090 & Table \\
\hline Ten_1 & $<-$ & Tr_1 & 0.0805 & 0.1271 & 0.6336 & 0.5263 & Maximum likelihod \\
\hline Ten 2 & $<-$ & $\operatorname{Tr} 2$ & 0.2688 & 0.1323 & 2.0310 & 0.0423 & loadings for the \\
\hline Ten_1 & $<-$ & Tr_2 & -0.3731 & 0.1271 & -2.9356 & 0.0033 & proposed \\
\hline Mov_FS & $<-$ & RC_FS & -0.3427 & 0.1109 & -3.0914 & 0.0020 & measurement mod \\
\hline
\end{tabular}

modifications were implemented. By correlating the variances that were not tested within the model, the fit of the model improved, however, the changes were not as great as the first two modifications. Other modifications between variances were suggested however, they were not supported by theory, and therefore, were not implemented.

An assessment of the fit of the re-specified model can be better understood by comparing the fit indices results between the proposed (Figure 3) and the re-specified model (Figure 5). The re-specified model suggests that there is a better fit as the chi-square and the degrees of freedom are much closer to each other indicating a better fitting model. This is also supported when comparing the other goodness of fit indices (Table 6). The CFI (0.86), which is independent of sample size is closer to 0.9, TLI is also closer to 1 and the lower RMSEA all corroborate a better model fit in the re-specified model. The CFI result also supports the

\begin{tabular}{|c|c|c|c|c|c|c|c|}
\hline Changes made from the previous test & Chi-square & $\mathrm{DF}$ & $P$-value & CFI & TLI & RMSEA & \\
\hline Proposed model & 139.22 & 36 & 0 & 0.36 & -0.178 & 0.23 (low $0.19-0.27$ ) & \\
\hline $\begin{array}{l}\text { Modification } 1 \\
\text { Add Comm } 1 \text { (expectations) - Coop } 1\end{array}$ & 99.61 & 36 & 0 & 0.6 & 0.24 & $\begin{array}{l}0.19 \\
\text { (low } 0.14-0.23 \text { ) }\end{array}$ & \\
\hline $\begin{array}{l}\text { Modification } 2 \\
\text { Add SV_FS - Coop_1 }\end{array}$ & 74.60 & 34 & 0.001 & 0.75 & 0.51 & 0.15 (lo $0.10-0.2$ ) & \\
\hline $\begin{array}{l}\text { Modification } 3 \\
\text { Add e9-e1 }\end{array}$ & 67.26 & 33 & 0.0004 & 0.79 & 0.57 & 0.14 (lo $0.0914-0.19)$ & \\
\hline $\begin{array}{l}\text { Modification } 4 \\
\text { Add e9-e7 }\end{array}$ & 62.44 & 32 & 0.001 & 0.81 & 0.61 & 0.134 (lo $0.835-0.183$ ) & \\
\hline $\begin{array}{l}\text { Modification } 5 \\
\text { Add e2 - e11 }\end{array}$ & 52.94 & 31 & 0.0083 & 0.86 & 0.71 & 0.1156 (lo $0.06-0.17$ ) & $\begin{array}{r}\text { Table } 5 . \\
\text { Summary of re- }\end{array}$ \\
\hline Re-specified model & 52.94 & 31 & 0.0083 & 0.86 & 0.71 & 0.1156 (lo $0.06-0.17$ ) & specification process \\
\hline
\end{tabular}


JSOCM

12,1

\section{6}

decision not to further modify the model as measures greater than 0.9 may result in overfitting (Bagozzi and Foxall, 1996).

The regression weights (Table 6) also suggest an improvement in the fit of the respecified model with 10 out of 31 relationships shown to be statistically significant. The previous regression weights (Table 4 ) supported 6 out of 21 relationships. The 10 additional relationships manifested from the modifications described earlier.

\section{Discussion}

Three research hypotheses were supported (H2, H6 and H7), one was partially supported (H8) and four were not supported (H1, H3-H5) (Table 7). Some of these findings are discussed below:

H2. There is a positive relationship between shared values and relationship commitment-supported.

H3. There is a positive relationship between shared values and trust - unsupported.

Because of the non-profit nature of social marketing, shared values was identified as a core component of longer-term partnerships (Niblett, 2005; Donovan and Henley, 2010). The synergy between shared values and commitment ensures that the partnerships are high impact (Weinreich, 1999, 2011; Crutchfield and Mc Leod Grant, 2008). A recent periodisation of social marketing partnerships identified shared value as a core characteristic of social marketing partnerships, which transcended the eras (Duane and Domegan, 2019). The respecified model did not support the positive relationship between shared values and trust (reliability and predictability). This suggests that trust may be implicit between

\begin{tabular}{lllrrrr}
\hline & & & Estimate & S.E. & \multicolumn{1}{c}{ C.R. } & $P$ \\
\hline Tr_1 & $<-$ & SV_FS & 0.0193 & 0.1406 & 0.1371 & 0.8909 \\
Tr_2 & $<-$ & SV_FS & -0.1431 & 0.1296 & -1.1039 & 0.2696 \\
Tr_1 & $<-$ & Comm_1 & 0.0954 & 0.1379 & 0.6917 & 0.4891 \\
Tr_2 & $<-$ & Comm_1 & 0.5675 & 0.1279 & 4.4360 & \\
Tr_1 & $<-$ & Comm_2 & -0.0787 & 0.1253 & -0.6282 & 0.5299 \\
Tr_2 & $<-$ & Comm_2 & -0.0708 & 0.1164 & -0.6078 & 0.5433 \\
Tr_1 & $<-$ & Comm_3 & -0.0675 & 0.1261 & -0.5354 & 0.5923 \\
Tr_2 & $<-$ & Comm_3 & -0.1203 & 0.1171 & -1.0275 & 0.3042 \\
RC_FS & $<-$ & MB_FS & 0.0348 & 0.1210 & 0.2876 & 0.7736 \\
RC_FS & $<-$ & Tr_1 & -0.0270 & 0.1165 & -0.2320 & 0.8165 \\
RC_FS & $<-$ & Tr_2 & 0.1634 & 0.1213 & 1.3469 & 0.1780 \\
RC_FS & $<-$ & SV_FS & 0.2942 & 0.1183 & 2.4866 & 0.0129 \\
Coop_1 & $<-$ & RC_FS & -0.1646 & 0.0756 & -2.1767 & 0.0295 \\
Coop_1 & $<-$ & Tr_1 & -0.1478 & 0.0643 & -2.2994 & 0.0215 \\
Coop_1 & $<-$ & Tr_2 & 0.1758 & 0.0767 & 2.2904 & 0.0220 \\
Ten_2 & $<-$ & Tr_1 & -0.0320 & 0.1292 & -0.2476 & 0.8044 \\
Ten_1 & $<-$ & Tr_1 & 0.0805 & 0.1241 & 0.6489 & 0.5164 \\
Ten_2 & $<-$ & Tr_2 & 0.2688 & 0.1325 & 2.0276 & 0.0426 \\
Ten_1 & $<-$ & Tr_2 & -0.3731 & 0.1273 & -2.9303 & 0.0034 \\
Mov_FS & $<-$ & RC_FS & -0.3198 & 0.1009 & -3.1694 & 0.0015 \\
Coop_1 & $<-$ & Comm_1 & 0.5247 & 0.0799 & 6.5678 & $* * *$ \\
Coop_1 & $<-$ & SV_FS & 0.4442 & 0.0733 & 6.0617 & $* * *$ \\
\hline
\end{tabular}

Table 6.

Re-specified model regression weights 


\section{Research hypotheses}

$H 1$ There is a positive relationship between mutual benefits and relationship commitment

H2 There is a positive relationship between shared values and relationship commitment

H3 There is a positive relationship between shared values and trust

H4 There is a positive relationship between communication and trust

H5 There is a positive relationship between relationship commitment and expectations of continuance

H6 There is a positive relationship between relationship commitment and cooperation

H7 There is a positive relationship between trust and cooperation

H8 There is a negative relationship between trust and tension
Supported/unsupported

Unsupported

Supported

Unsupported

Partially supported

Unsupported

Supported

Supported

Partially supported
Social marketing partnership model

Table 7. Research hypotheses

organisations who have shared values, and therefore, trust does not act as a mediating variable as goals converge (Legarde et al., 2005; Himmelman, 2001; Hastings, 2003).

Likewise, a direct path was drawn between shared values and cooperation within the respecified model - a relationship that had not been hypothesized. This relationship exhibited the second highest critical ratio. Once again, the presence of goal convergence may suggest that trust is implicit, and therefore, not a mediating variable (Legarde et al., 2005). This would support the rational to bypass trust as a mediating variable and accept the direct path between shared values and cooperation.

Two other relationships related to cooperation were also supported in the model, $\mathrm{H} 6$ and H7:

H6. There is a positive relationship between relationship commitment and cooperation.

H7. There is a positive relationship between trust and cooperation.

The hypothesized relationship between trust and tension was partially supported within the re-specified model:

H8. There is a negative relationship between trust and tension.

Following the EFA both trust and tension were shown to have two-factor loadings/principle components. These factor loadings were labelled as reliability (trust_1) and predictability (trust 2) and tension (tension_1) and tension handling (tension_2). The re-specified model showed that the relationship between reliability (trust_1), tension and tension handling was not supported. The relationship between predictability (trust_2) tension and tension handling was supported. This suggests that predictability reduces the development within partnership relationships. Consequently, with less predictable partners there is a greater requirement for conflict handling:

H4. There is a positive relationship between communication and trust.

Trust, measured as reliability and predictability was hypothesized to have a positive relationship with communication measured as expectations, information sharing and type of information. This hypothesis was partially supported. The data suggests that there is a positive relationship between predictability and expectations. Within the social marketing literature, the need to manage the expectations of the partners is paramount (Legarde et al., 2005). 
JSOCM

12,1

The relationship between the facets of trust (reliability) and communication (information sharing and information type) were not supported. This could be related to the partner prioritising the communications. Within the social marketing literature, Himmelman (2001) indicated that information sharing was one of the first points on their partnership continuum. As the majority of participants in the survey stated the behavioural change partnership they were thinking of was mature or very mature, the lack of significance of information sharing could be attributed to the fact that their relationship had moved beyond this point.

Associated with this issue, one of the newly specified direct paths suggests there is a positive relationship between the communication of expectation and cooperation. This direct path was identified as most significant in the model. Communication was hypothesized to be mediated through trust. However, more specifically, when referring to the communication of expectations, trust as a mediating variable may not be needed. The scales that contributed to the communication of expectations were associated with formal written agreements and the explicit articulation of the expectations of the parties involved. When the roles and responsibilities are clearly defined trust may not be needed as a mediating factor. Within the case study, written agreements were not deemed as necessary between partners who already had a pre-existing relationship. However, when the large financial investment was required a formal written agreement was deemed essential. As previously stated, cooperation is related to the interdependence between parties, which is aligned with the management of expectations, through a willingness to share tangible and intangible resources. This finding was supported in the literature through Legarde et al.'s (2005) taxonomy.

$H 1$ and $H 5$ were unsupported. The first was the relationship between mutual benefits and relationship commitment. The second stated there is a positive relationship between relationship commitment and expectations of continuance:

H1. There is a positive relationship between mutual benefits and relationship commitment.

This hypotheses was unsupported, perhaps, because social marketing focusses on the benefits of society as opposed to the partner involved. Reflecting on the characteristics of social marketing as outlined by Brennan et al. (2016), the non-profit motive, high involvement decision-making and the complexity of the social issues we seek to address, the exchange must take place to motivate the partnership to continue. Although this hypothesis was rejected, the mutual benefit should undergo further testing particularly in relation to public-private partnerships, which was outside the boundaries of the research. The importance of different types of partnerships within the SDGs (\#17) also suggests this hypothesis should undergo further testing.

\section{Conclusion}

Every country on every continent is experiencing complex, local-to-global economic, social and environmental issues. Explicitly recognising the links between our economy, our environment and our health the UN's 17 SDGs declare cross-sectoral partnerships to be the key to responding to and resolving systemic challenges. Like partnerships for the goals, a shared vision and goals that places social good, people and the planet at the centre are fundamental to social marketing activities. For social marketing at the frontiers of social, transformation and systemic change, the real strength of partnership thinking and this model lies not in the once off co-operation activities for a campaign, but in the multi-tier, 
multi-stakeholder relationships ebbing and flowing around shared values, mutual benefit, communication, trust and commitment for a sustainable future for all.

This research directly responds to the UNs need for further research to support the development of transformational partnerships so that change activities can be scaled up and accelerated. The process underpinning the development of a social marketing partnership model was presented. This research makes 4 contributions, which are discussed below, with suggestions for further research.

1. The operationalising of social marketing partnership constructs, which can be used to support the partnership selection process.

Previous research suggested there was a disconnect between the theory and practice of social marketing partnerships. Partnerships is a nebulous term used within social marketing, which has suffered from definitional ambiguity. Characteristics of social marketing partnerships have been used to assess why partnerships have been successful or not, however, these characteristics have not previously been operationalised. The operationalising of social marketing construct definitions could provide clarity in relation to the partnership selection process.

2. The development of social marketing partnership scales, which could be used to evaluate existing multi-stakeholder partnership relationships and guide their long term implementation.

The newly developed social marketing partnership scales were used to test the proposed social marketing partnership model, however, in practice, these could also be used to help evaluate social marketing partnerships across different points in time. For the first time, social marketing partnership scales have been developed and tested within the domain. On a practical level using these scales to evaluate partnerships could guide decision-making and strategy formation in relation to whether to continue or terminate partnership arrangements or to search for additional partners to reduce resource and competency deficits.

3. Morgan and Hunt's Relationship and Commitment model (1994) was extended and tested within the social marketing domain.

Morgan and Hunt's (1994) model initially developed in the commercial marketing sector is one of the best-known relationship marketing theories guiding the development of long term cooperative behaviours. This model was developed in response to a paradigm shift towards relational network approaches to compete in competitive marketplaces. Social marketing is going through a similar shift, now embracing complex exchanges so change agents can compete against problematic behaviours over time. Trust and commitment are central constructs in this regard. Figure 6 illustrates the new social marketing partnership model. With five modifications, the original hypothesized social marketing partnership model was shown to have a better fit. Two new paths that were not previously hypothesized had the highest statistical significance. These two paths were:

- the direct relationship between shared values and cooperation; and

- the relationship between the communication of expectations and cooperation.

Whilst the rigorous multi-method model building process suggests that the constructs hypothesized do exist, a cautious approach must be undertaken when discussing the strength of the interrelationships between constructs because of a small sample size. However, the model testing process also suggests that the operationalisation of the social marketing partnership model is feasible and possible parameter estimates from what is taken as the most theoretically consistent statistical model for data of this type. Using the current parameters from this and similar research, future researchers can now consider the 


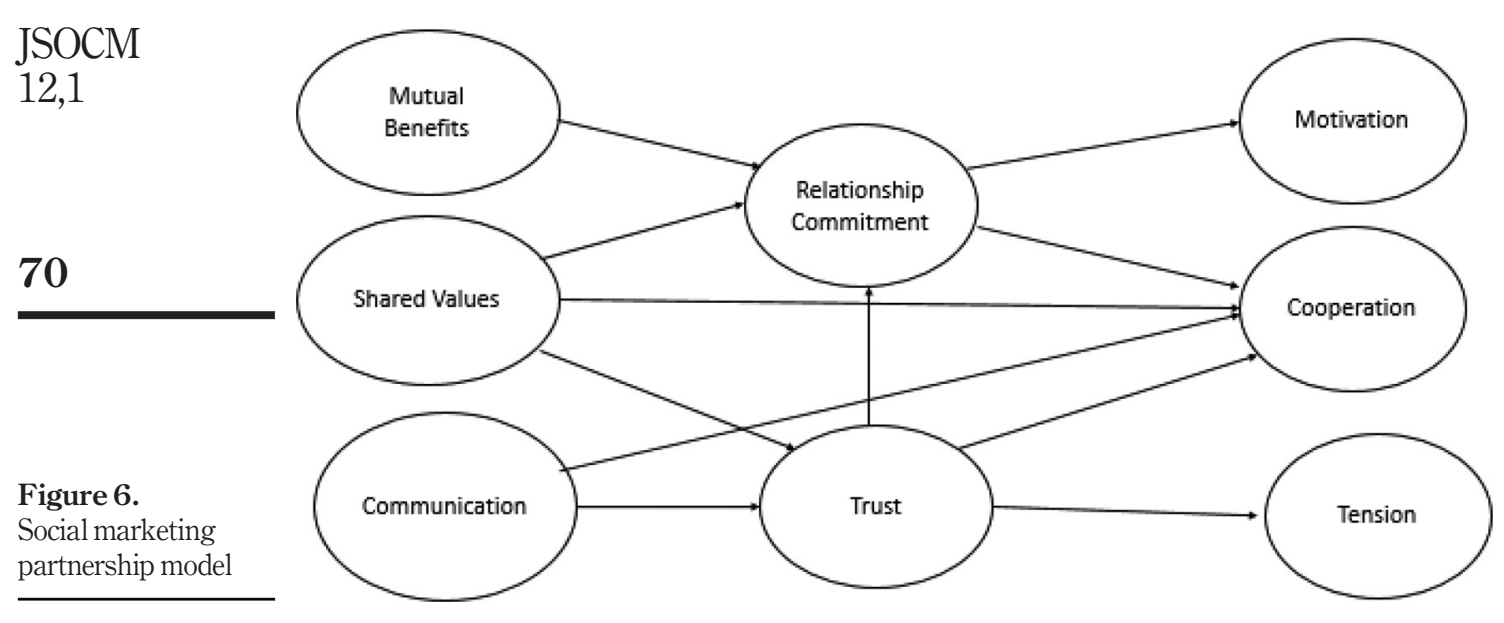

application of Monte Carlo simulations to further assess the current theory as expounded. This can be done by taking the current parameter estimates and drawing a series of repeated samples to evaluate the type of samples that would be required to further test the theory. The current work now provides us with a strategy, akin to that used in obtaining sample power calculations, but in the current case to further test the effectiveness and correctness of the proposed model (Muthén and Muthén, 2002). It is likely that with a small social marketing community there is always going to be dealing with small sample sizes in this type of research, so a crucial factor in this context will be the psychometric properties of the measures and the strength of the relationship between the measures. In the current analysis, we can see that the psychometric properties of the measures, based on this and other research have been shown to be good; the concern then is with the strength of the relationships between the measures and in this context we have provided approximate estimates that can be further tested and within the context of a testable theory.

4. Strengthening the implementation of partnership relationships.

The aim of SDG \#17 is to "strengthen the means and implementation and revitalise the global partnership for sustainable development” (UN Sustainable Development Goals, 2021). The findings of this research align with the vision for SDG \#17 and make the development of a "partnership-enabling ecosystem" more realistic by identifying and testing the relationships between core characteristics of behavioural and social change partnerships. This research has shown the important role of trust, commitment, shared values and cooperation when addressing behavioural issues. In particular, this research has identified the active ingredients for effective partnerships. This knowledge can support capacity and skill building between stakeholders, partners and wider networks fostering more strategic collective action. The model could be used as a framework that can guide the initiation and evaluation of partnership relationships. This is essential when trying to nurture sustainable partnerships and nurture them in the long term as social marketers will have a better understanding of how to establish, develop and maintain partnerships.

\section{Future research}

This model should be further tested in both developed and developing economies to identify if key social marketing constructs exist in different contexts. This research was 
also conducted with experts in behavioural change, other types of stakeholders, such as those in the public-private sector, should be invited to participate in further iterations of this research to determine if they construct identified transfer to, for example, the commercial setting.

This research adopted a cross-sectional perspective, the presence of time was determined as a catalyst for strengthening trust and relationship commitment. There would be merit to testing this model with partnerships that are at different stages of development, initiation vs long-term partnerships.

As partnerships evolve over time or not, relationships may grow and deepen as stakeholders move from working together on a campaign to another intervention. New opportunities for alliances and collaboration are constantly emerging. Innovations in technologies, such as participatory, stakeholder and network software, fuel greater communication and information flow to say nothing of the shifts in mutual values, such as climate action and healthy environments are bringing. Understanding the early formation and ongoing development of social marketing partnerships in light of the ubiquity of change is critical if social marketing is to deliver on the UN's SDG \#17, multi-stakeholder partnerships for sustainable development. This conceptualisation would assist in guiding practitioners on how to initiate and sustain partnerships over time.

\section{References}

Anderson, J.C. and Gerbing, D.W. (1988), "Structural equation modeling in practice: a review and recommended Two-Step approach”, Psychological Bulletin, Vol. 103 No. 3, pp. 411-423.

Anderson, J.C. and Narus, J.A. (1990), "A model of distributor firm and manufacturer firm working partnerships", Journal of Marketing, Vol. 54 No. 1, p. 44.

Andreasen, A.R. (2001), "Intersector transfer of marketing knowledge", In Boom, P. and Gundlach, G. (Eds), Handbook of Marketing and Society, Sage Publications, CA.

Aulakh, P.S., Kotabe, M. and Sahay, A. (1996), "Trust and performance in Cross-Border marketing partnerships: a behavioral approach”, Journal of International Business Studies, Vol. 27 No. 5, pp. 1005-1032.

Bagozzi, R., P. (1975), “Marketing as exchange”, Journal of Marketing, Vol. 39 No. 4, pp. pp32-39.

Bagozzi, R.P. and Foxall, G.R. (1996), "Construct validation of a measure of Adaptive-Innovative cognitive styles in consumption”, International Journal of Research in Marketing, Vol. 13 No. 3, pp. 201-213.

Baloch, M.S., Taj, S., Kiazai, N. and Arshad, T. (2020), "Resistance, resisting and resisters: the case of a social marketing partnership in Balochistan", Journal of Education and Humanities Research, University of Balochistan, Quetta-Pakistan, pp. 13-39.

Baumgartner, H. and Homburg, C. (1996), "Applications of structural equation modeling in marketing and consumer research: a review”, International Journal of Research in Marketing, Vol. 13 No. 2 , pp. 139-161.

Bearden, W.O., Netemeyer, R.G. and Haws, K.L. (2011), "Handbook of marketing scales", Multi-item Measures for Marketing and Consumer Behavior Research, Sage Publications.

Bentler, P.M. and Yuan, K.H. (1999), "Structural equation modeling with small samples: Test statistics", Multivariate Behavioral Research, Vol. 34 No. 2, pp. 181-197.

Bhattacharya, C.B. and Bell, P.D. (1999), “Care's experiences with corporate alliances”, Social Marketing Quarterly, Vol. 5 No. 3, pp. 10-12. 
JSOCM

12,1

Biroscak, B.J., Schneider, T., Panzera, A.D., Bryant, C.A., McDermott, R.J., Mayer, A.B., Khaliq, M., Lindenberger, J., Courtney, A.H. and Swanson, M.A. (2014), "Applying systems science to evaluate a community-based social marketing innovation: a case study", Social Marketing Quarterly, Vol. 20 No. 4, pp. 247-267.

Brennan, L., Previte, J. and Fry, M.L. (2016), "Social marketing's consumer myopia: Applying a behavioural ecological model to address wicked problems", Journal of Social Marketing, Vol. 6 No. 3, pp. 219-239.

Byrne, B.M. (2001), "Structural equation modeling with AMOS, EQS, and LISREL: Comparative approaches to testing for the factorial validity of a measuring instrument", International Journal of Testing, Vol. 1 No. 1, pp. 55-86.

Byrne, B.M. (2010), Structural Equation Modeling with AMOS - Basic Concepts, Applications and Programming, Routledge Taylor and Francis Group, London.

Choi, C., Eldomiaty, T. and Kim, S. (2007), "Consumer trust, social marketing and ethics of welfare exchange”, Journal of Business Ethics, Vol. 74 No. 1, pp. 17-23.

Churchill, G.A. Jr (1979), “A paradigm for developing better measures of marketing constructs”, Journal of Marketing Research, Vol. 16 No. 1, pp. 64-73.

Crutchfield, L.R. and Mc Leod Grant, H. (2008), Forces for Good: The Six Practices of High - Impact NonProfits, John Wiley and Sons, San Francisco.

Dillman, D.A. (2000), Mail and Internet Surveys: The Tailored Design Method, John Wiley and Sons.

Domegan, C. (2021), "Social marketing and behavioural change in a systems setting", Current Opinion in Environmental Science and Health, Vol. 23, p. 100275.

Domegan, C., McHugh, P., Devaney, M., Duane, S., Hogan, M., Broome, B.J., Layton, R.A., Joyce, J., Mazzonetto, M. and Piwowarczyk, J. (2016), "Systems-thinking social marketing: conceptual extensions and empirical investigations", Journal of Marketing Management, Vol. 32 Nos 11/12, pp. 1123-1144.

Domegan, C., McHugh, P., Flaherty, T. and Duane, S. (2019), “A dynamic stakeholders' framework in a marketing systems setting”, Journal of Macromarketing, Vol. 39 No. 2, pp. 136-150.

Donovan, R. and Henley, N. (2010), Principles and Practice of Social Marketing: An International Perspective, Cambridge University Press, Cambridge.

Duane, S. and Domegan, C. (2019), "Social marketing partnerships: Evolution, scope and substance", Marketing Theory, Vol. 19 No. 2, pp. 169-193.

Duane, S., Domegan, C., McHugh, P. and Devaney, M. (2016), "From restricted to complex exchange and beyond: social marketing's change agenda", Journal of Marketing Management, Vol. 32 Nos 9/ 10, pp. 856-876.

Eagle, L., Hay, R. and Farr, M. (2016), "Harnessing the science of social marketing and behaviour change for improved water quality in the GBR: background review of the literature".

Flaherty, T., Domegan, C., Duane, S., Brychkov, D. and Anand, M. (2020), "Systems social marketing and macro-social marketing: a systematic review", Social Marketing Quarterly, Vol. 26 No. 2, pp. 146-166.

Fornell, C. and Larcker, D.F. (1981), "Evaluating structural equation models with unobservable variables and measurement error", Journal of Marketing Research, Vol. 18 No. 1, pp. 39-50.

Ghauri, P. and Gronhaug, K. (2010), Research Methods in Business Studies Essex, Pearson Education Limited.

Gordon, R. (2013), "Unlocking the potential of upstream social marketing", European Journal of Marketing, Vol. 47 No. 9, pp. 1525-1547. 
Gummesson, E. (1994), "Making relationship marketing operational”, International Journal of Service Industry Management, Vol. 5 No. 5, pp. 5-20.

Hair, J.F., Black, W.C., Babin, B.J., Anderson, R.E. and Tatham, R.L. (2006), Multivariant Data Analysis, Pearson Prentice Hall.

Hastings, G. (2003), "Relational paradigms in social marketing", Journal of Macromarketing, Vol. 23 No. 1, pp. 6-15.

Hastings, G. and Saren, M. (2003), "The critical contribution of social marketing - Theory and practice”, Marketing Theory, Vol. 3 No. 3, pp. 305-322.

Himmelman, A.T. (2001), "On coalitions and transformation of power relations: Collaborative betterment and collaborative empowerment", American Journal of Community Psychology, Vol. 29 No. 2, pp. 277-284.

Hooper, D., Coughlan, J. and Mullen, M.R. (2010), "Structural equation modelling: Guidelines for determining model fit", Electronic Journal of Business Research, Vol. 6 No. 1, pp. 53-60.

Hu, L.T. and Bentler, P.M. (1999), "Cut-off criteria for fit indexes in covariance structure analysis: Conventional criteria Versus", Structural Equation Modeling: A Multidisciplinary Journal, Vol. 6 No. 1, pp. 1-55.

Hunt, S.D. (2010a), On the Morphology of Theory. Marketing Theory: Foundations, Controversy, Strategy, Resource-Advantage Theory, M.E. Sharpe, London.

Hunt, S.D. (2010b), Theory: Issues and Aspects. Marketing Theory: Foundations, Controversy, Strategy, Resource Advantage Theory, M.E. Sharpe, London.

Jarvis, C.B., Mackenzie, S.B. and Podsakoff, P.M. (2003), "A critical review of construct indicators and measurement model misspecification in marketing and consumer research", Journal of Consumer Research, Vol. 30 No. 2, pp. 199-218.

Johansson, C., Bedggood, R., Farquharson, K. and Perenyi, A. (2018), "Shared leadership as a vehicle to healthy service eco-systems: practical or fanciful?", Journal of Social Marketing, Vol. 8 No. 2, pp. 159-181.

Kennedy, A.M. (2016), "Macro-social marketing", Journal of Macromarketing, Vol. 36 No. 3, pp. 354-365.

Lambe, C.J., Spekman, R.E. and Hunt, S.D. (2002), "Alliance competence, resources, and alliance success: conceptualization, measurement, and initial test", Journal of the Academy of Marketing Science, Vol. 30 No. 2, pp. 141-158.

Lee, N., Achermann, K., Ehrumann, R. and Mintz, J. (2005), "The challenges and rewards of partnering with the private sector to achieve social marketing objectives", Social Marketing Quarterly, Vol. 11 No. 3-4, pp. 51-59.

Lee, N.R. (2020), Social Marketing Quarterly, Vol. 26 No. 1, pp. 3-13.

Lefebvre, R.C. (2012), "Transformative social marketing: co-creating the social marketing discipline and Brand", Journal of Social Marketing, Vol. 2 No. 2, pp. 118-129.

Legarde, F., Doner, L., Donovan, R.J., Charney, S. and Griser, M. (2005), "Partnerships from a downstream perspective: the role strategic alliances play in implementing social marketing programmes", Social Marketing Quarterly, Vol. 11 No. 3-4, pp. 38-45.

MacMillan, K., Money, K., Money, A. and Downing, S. (2005), "Relationship marketing in the not-forprofit sector: an extension and application of the commitment-trust theory", Journal of Business Research, Vol. 58 No. 6, pp. 806-818.

Mohr, J. and Spekman, R. (1994), "Characteristics of partnership success: partnership attributes, communication behavior, and conflict resolution techniques", Strategic Management Journal, Vol. 15 No. 2, pp. 135-152. 
JSOCM

12,1

Mohr, J.J., Fisher, R.J. and Nevin, J.R. (1996), "Collaborative communication in interfirm relationships: moderating effects of integration and control", Journal of Marketing, Vol. 60 No. 3, pp. 103-115.

Morgan, R.M. and Hunt, S.D. (1994), “The commitment-trust theory of relationship marketing”, Journal of Marketing, Vol. 58 No. 3, pp. 20-38.

Muthén, L.K. and Muthén, B.O. (2002), "How to use a monte carlo study to decide on sample size and determine power", Structural Equation Modeling: A Multidisciplinary Journal, Vol. 9 No. 4, pp. 599-620.

Niblett, G.R. (2005), "Stretching the limits of social marketing partnerships, upstream and downstream: Setting the context for the 10th innovations in social marketing conference", Social Marketing Quarterly, Vol. 11 No. 3-4, pp. 9-15.

Ping, J.R.A. (2004), "On assuring valid measures for theoretical models using survey data”, Journal of Business Research, Vol. 57 No. 2, pp. 125-141.

Platt, J. (2006), What Can Case Studies Do? Case Study Research, Sage, London.

Shook, C., Ketchen, D.J., Hult, T.M. and Kacmar, K.M. (2004), "Research notes and commentaries: an assessment of the use of structural equation modeling in strategic management research", Strategic Management Journal, Vol. 25 No. 4, pp. 397-404.

Singer, B. and Kayson, S. (2004), "Partnerships, alliances, and stakeholder communication", Social Marketing Quarterly, Vol. 10 No. 2, pp. 67-71.

Sutton, R.I. and Staw, B.M. (1995), "What theory is not”, Administrative Science Quarterly, Vol. 40 No. 3, pp. 371-384.

Tapp, A.R., Brophy, R., Carausan, M., Carruthers, J., Peattie, S., Revill, S., Chamberlain, M., Lee, N., Sherif, S., Beall, T. and Morgan, M. (2013), Consensus Definition of Social Marketing.

Thomas, J. (2008), "Happily ever after...? partnerships in social marketing", Social Marketing Quarterly, Vol. 14 No. 1, pp. 72-75.

Truong, V.D. (2017), "Government-led macro-social marketing programs in vietnam: Outcomes, challenges, and implications", Journal of Macromarketing, Vol. 37 No. 4, pp. 409-425.

Truong, V.D. and Dietrich, T. (2018), "Master's thesis research in social marketing (1971-2015)", Journal of Social Marketing, Vol. 8 No. 1, pp. 58-98.

Truong, V.D., Saunders, S.G. and Dong, X.D. (2019), "Systems social marketing: a critical appraisal”, Journal of Social Marketing, Vol. 9 No. 2, pp. 180-203.

UN Sustainable Development Goals (2021), "Revitalize the global partnership for sustainable development [online]. UN sustainable development goals", available at: https://sdg-tracker.org/ global-partnerships (accessed 22 March 2021).

United Nations (2019), "Sustainable development goals”, United Nations, available at: www.un.org/ sustainabledevelopment/sustainable-development-goals/ (accessed 7 November 2019).

United Nations (2020), The SDG Partnership Guidebook: A Practical Guide to Building High Impact Multi-Stakeholder Partnerships for the Sustainable Development Goals, United Nations.

Weinreich, N.K. (1999), Hands-On Social Marketing- A Step-by-Step Guide, Page Publications Inc, London.

Weinreich, N.K. (2011), Hands on Social Marketing- A Step by Step, SAGE Publications Inc, London.

Wymer, W. (2021), “Addressing complex social problems with a multi-environmental stakeholder coalition”, International Review on Public and Non-Profit Marketing, Vol. 18, pp. 1-16.

Zürcher, C. (2018), "A theory of democratisation through peace-building", Conflict, Security and Development, Vol. 18 No. 4, pp. 283-299. 


\section{Further reading}

Bearden, W.O., Netemeyer, R.G. and Haws, K.L. et al. (2011), Handbook of Marketing Scales: Multi-Item Measures for Marketing and Consumer Behaviour Research, Sage, London.

Selnes, F. (1998), "Antecedents and consequences of trust and satisfaction in buyer-seller relationships", European Journal of Marketing, Vol. 32 Nos 3/4, pp. 305-322.

Tapp, A., Carausan, M.R.B., Carruthers, J., Peattie, S., Revill, S., Chamberlain, M., Lee, N., Sherif, S., Morgan, T.B., Lellig, C., Suggs, S. and French, J. (2013), "The iSMA, ESMA and AASM consensus definition of social marketing. iSMA: iSMA, ESMA and AASM".

\section{Corresponding author}

Sinead Duane can be contacted at: sinead.duane@nuigalway.ie

For instructions on how to order reprints of this article, please visit our website: 